\title{
TITLE: INTEGRATED OUTCROP AND SUBSURFACE STUDIES OF THE INTERWELL ENVIRONMENT OF CARBONATE RESERVOIRS: CLEAR FORK (LEONARDIAN AGE) RESERVOIRS, WEST TEXAS AND NEW MEXICO
}

\author{
SEMI-ANNUAL REPORT \\ Reporting Period: October 1, 1999, through March 31, 2000 \\ Authors: F. Jerry Lucia and Stephen E. Laubach
}

April 2000

Contract No. DE-AC26-98BC15105--02

Contractor Name and Address: Bureau of Economic Geology (BEG), The University of Texas at Austin, University Station, Box X, Austin, Texas 78713-8924 


\section{DISCLAIMER}

This report was prepared as an account of work sponsored by an agency of the United States Government. Neither the United States Government nor any agency thereof, nor any of their employees, makes any warranty, express or implied, or assumes any legal liability or responsibility for the accuracy, completeness, or usefulness of any information, apparatus, product, or process disclosed, or represents that its use would not infringe privately owned rights. Reference herein to any specific commercial product, process, or service by trade name, trademark, manufacturer, or otherwise does not necessarily constitute or imply its endorsement, recommendation, or favoring by the United States Government or any agency thereof. The view and opinions of authors expressed herein do not necessarily state or reflect those of the United States Government or an agency thereof. 
SEMI-ANNUAL TECHNICAL PROGRESS REPORT

for

\title{
INTEGRATED OUTCROP AND SUBSURFACE STUDIES OF THE INTERWELL ENVIRONMENT OF CARBONATE RESERVOIRS: CLEAR FORK (LEONARDIAN AGE) RESERVOIRS, WEST TEXAS AND NEW MEXICO
}

\author{
Contract No. DE-AC26-98BC15105
}

\begin{abstract}
Results and Discussion

We have completed 18 months of this project and are reporting progress we have made in the areas of fracture and reservoir modeling.

$\underline{\text { Task 1a. Construct Model of Outcrop Stratigraphic Framework }}$

This task has been completed.

$\underline{\text { Task 1b. Construct Model of Fine-Scale Petrophysical Heterogeneity }}$

This task has been completed.

Task 1c. Construct Model of Fracture Porosity and Permeability

The object of this task is to characterize fracture porosity and distribution in the Wasson Clear Fork reservoir and to determine the effects of fractures on well performance. The approach is to measure fracture attributes in an analog outcrop, to develop models of fracture spacing and aperture, and to apply this information to the South Wasson Clear Fork reservoir. A data set has been collected from outcrops of the Clear Fork Formation, Apache Canyon, Sierra Diablo Mountains, West Texas, and a summary of the results is presented.
\end{abstract}




\section{$\underline{\text { Fracture Spacing and Aperture }}$}

The outcrop contains numerous fractures. We have collected fracture-spacing and aperture values from four scan lines. Fractures obviously related to structural uplift were eliminated from the data set. The results show power-law scaling in fracture aperture distribution (fig. 1a). Fracture spacing, however, shows an exponential scaling rather than the expected power-law scaling (fig. 1b).
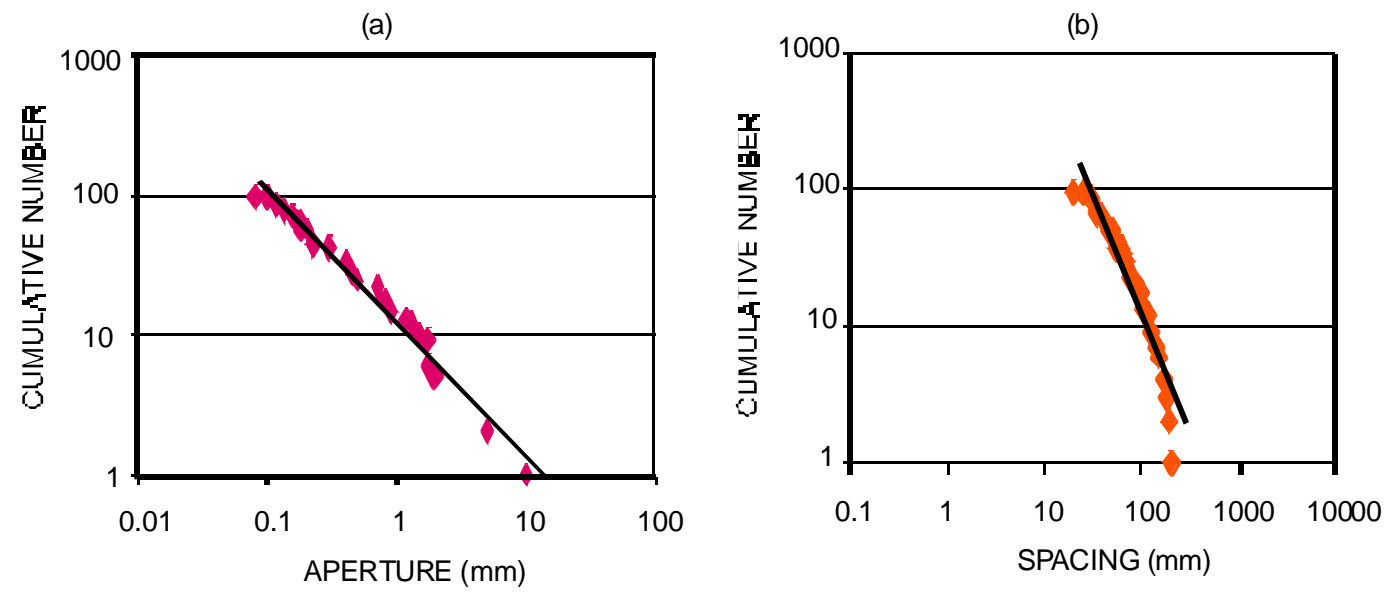

Figure 1. Distribution of fracture aperture and spacing from scanline 1, Clear Fork Formation, Apache Canyon, Sierra Diablo Mountains, West Texas.

Fracture Connectivity

Fracture connectivity is being addressed by comparing independent fracture length and aperture measurements. Such a relation would permit length estimates to be made from aperture measurements in boreholes (where fracture lengths cannot be determined directly because they exceed the borehole diameters). An analysis of our data shows a power-law relationship between length and aperture for fractures (fig. 2). 


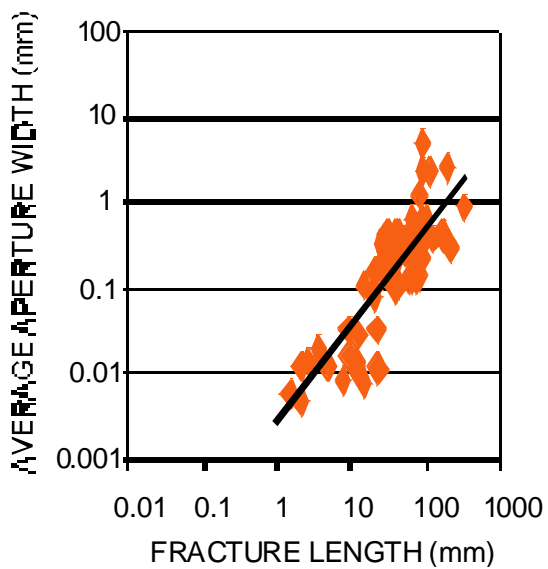

Figure 2. A plot of fracture length and average aperture width measured independently, showing a power-law scaling function.

\section{Task 2b. Gather Subsurface Fracture Data}

\section{Fracture Quality}

An extensive data set has been collected from South Wasson Clear Fork (SWCF) cores. Thin sections have been prepared and described. A critical observation is the timing between fracture formation and fracture cements; cements are classified with reference to the timing of fracture opening. Prekinematic, synkinematic, and postkinematic cements, respectively, predate, are contemporaneous with, and postdate fracture opening. The width of fractures that are lined with synkinematic cement but that preserve fracture porosity with respect to synkinematic cement is referred to as the emergent threshold (Laubach, in preparation). Dolomite appears to be the synkinematic cement in the SWCF, and the emergent threshold is about 100 microns. The postfracture cement is anhydrite.

The quality of the fractures observed in SWCF cores is determined by comparing the amount of postkinematic cement (anhydrite) with the amount of porosity plus postkinematic cement. This is called the degradation index (Laubach, in preparation). This index has been calculated for 49 samples, of which 8 had open fractures, 12 had partly filled fractures, 16 had filled fractures, and 13 had no fractures (fig. 3). Low degradation implies that large fractures or networks of fractures are open and capable of transmitting fluids. 
Inspection of figure 3 shows that there is a range of degradation-index values. Because many of the samples with an index of less than $50 \%$ have no fractures, they do not provide a test of the degradation-index predictions, nor is there a clear separation between open, partly open, and closed fractures. This situation is partly a reflection of two other factors. First, the fractures span a range of sizes and there is a degree of size dependence on postkinematic fracture fill. Second, crosscutting relations suggest that at least two sets of fractures are present. Moreover, we speculate that multiple generations of anhydrite precipitation may have occurred. From the fracture analysis we conclude that where the fractures are filled, most fractures in the SWCF reservoirs are filled with anhydrite.

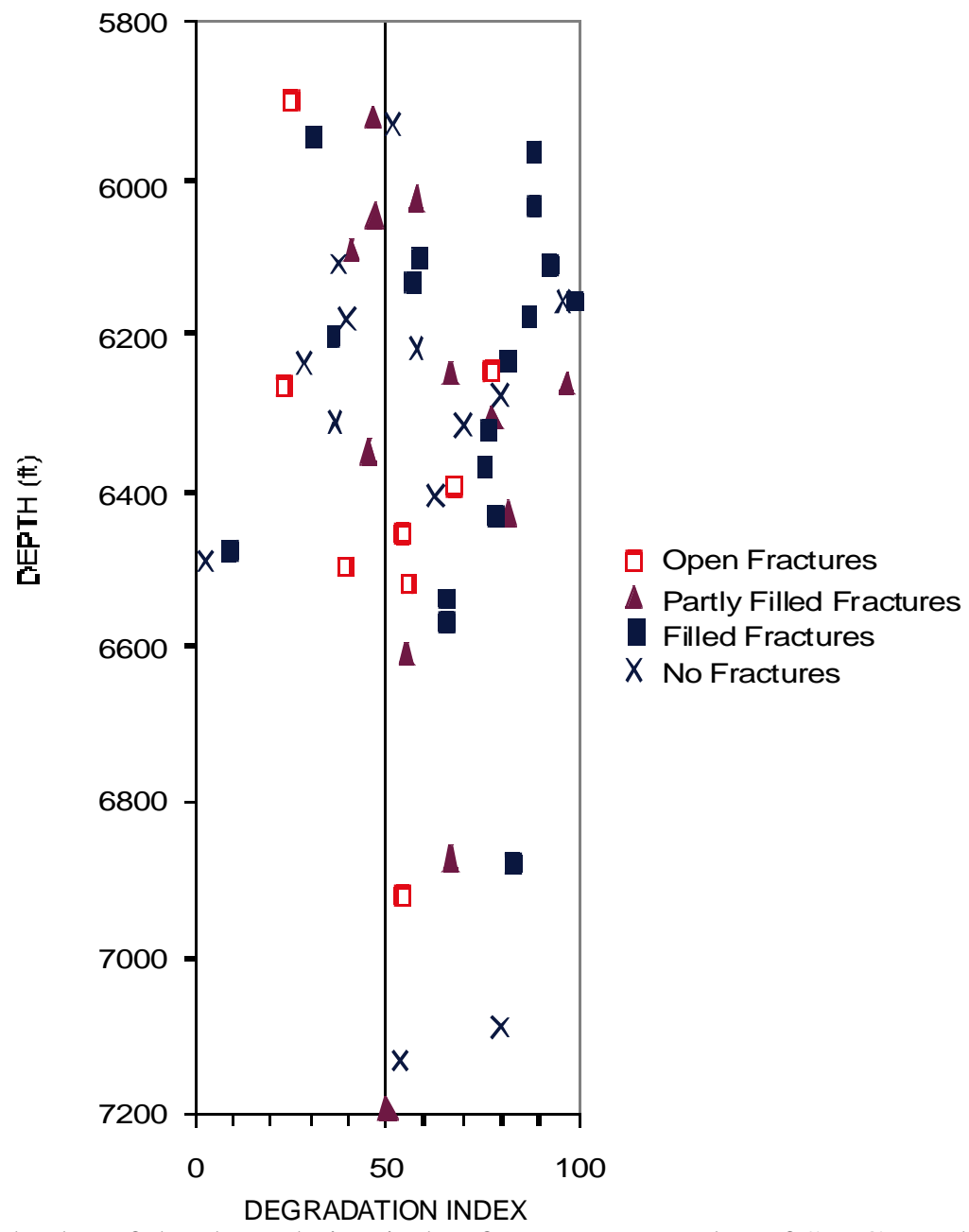

Figure 3. Depth plot of the degradation index from core samples of SWCF well 7531. The degradation index is the ratio of postkinematic cement (anhydrite) to postkinematic cement plus pore space. 
Many microfractures are not apparent when using conventional imaging methods, but they can be quantified by using SEM-based CL. New imaging methods are being applied and tested to push the size of microfractures that can be accurately measured to smaller sizes. We recently discovered that the use of certain filter combinations in scanned CL imaging permits features to be observed that are not apparent by any other CL method.

\section{$\underline{\text { Task 2c. Construct Subsurface Reservoir Model }}$}

The construction of the SWCF fluid-flow model continues. Westport Labs, using a centrifuge technique, measured drainage and imbibition capillary-pressure curves for six outcrop samples. The measurements were conducted at reservoir temperature using dead crude from the South Wasson Clear Fork reservoir and simulated reservoir brine. The samples were aged at reservoir temperature after drainage in order to simulate subsurface wettability. Preliminary calculations using the imbibition capillary-pressure curves indicate a minor effect of capillary pressure on relative permeability scaleup.

Fifty additional samples from South Wasson Clear Fork well 7531 have been drilled for further centrifuge measurements to quantify initial-residual oil curves and end-point saturation variability.

\section{Discussion of Fracture Results}

The timing of dolomite formation relative to fracture formation is a key issue in our efforts to predict fracture permeability in the SWCF reservoir. Although synkinematic dolomite has been observed, developing criteria for identifying synkinematic dolomite in the matrix remains a problem. The SWCF reservoir is completely dolomitized, and there are most likely multiple periods of dolomitization. Methods for distinguishing the various periods of dolomitization have not yet been established. However, phases of dolomite cement have been successfully distinguished in other dolomite reservoirs by using conventional CL, so the prospects are good for successfully unraveling these relations by using the more powerful imaging methods now available. 
The timing of anhydrite formation relative to fracture formation is also a key issue in predicting fracture permeability in the SWCF reservoir. Anhydrite is a diagenetic mineral like dolomite and, although it fills fractures, is widespread in the matrix as replacement, displacement, and pore-filling anhydrite. The diagenetic history of anhydrite is complicated, and techniques for unraveling the history have not been developed. It is likely that some anhydrite was originally the hydrous form called "gypsum." It is clear that some calcium sulfate minerals are penecontemporaneous with early dolomite formation and that others formed later. We cannot assume that all the anhydrite is postkinematic, and methods for distinguishing various phases of anhydrite emplacement need to be developed before an accurate accounting of postkinematic anhydrite cement can be made. 